\title{
Aluminum Potassium Sulfate and Tannic Acid - A New Option for the Treatment of Grade 3 Hemorrhoids
}

\author{
Yong Hee Hwang \\ Department of Surgery, Sahmyook Medical Center, Seoul, Korea
}

\section{See Article on Page 103-105}

Injection therapy has a long history of being used for the treatment of hemorrhoids. However, the previous results on injection therapy for its complication rates and severity were not promising [1]. In this respect, aluminum potassium sulfate and tannic acid (ALTA) therapy could be a new promising option for the treatment of internal hemorrhoids [2]. However, some complications have been reported for ALTA therapy [3]. Thus, the learning of a precise surgical procedure and careful selection of the patients are vital. In addition, over-dosage and injection at an inappropriate location or depth frequently lead to serious complications. Application of ALTA therapy for the treatment of internal hemorrhoids may be a good choice, but still its efficacy for the treatment of external hemorrhoids and skin tags is limited. Thus, the surgeon should consider combined therapy (a hemorrhoidectomy and ALTA therapy) for the treatment of mixed hemorrhoids. Even though ALTA therapy has better treatment results than PAO therapy, well-controlled surgery and patient selection are still needed.

\section{CONFLICT OF INTEREST}

No potential conflict of interest relevant to this article was reported.

\section{REFERENCES}

1. Barwell J, Watkins RM, Lloyd-Davies E, Wilkins DC. Life-threatening retroperitoneal sepsis after hemorrhoid injection sclerotherapy: report of a case. Dis Colon Rectum 1999;42:421-3.

2. Yano T, Yano K. Comparison of injection sclerotherapy between $5 \%$ phenol in almond oil and aluminum potassium sulfate and tannic acid for grade 3 hemorrhoids. Ann Coloproctol 2015; 31:103-5

3. Lim SW. Aluminum potassium sulfate and tannic Acid injection for hemorrhoids. J Korean Soc Coloproctol 2012;28:73-7.

Correspondence to: Yong Hee Hwang, M.D.

Department of Sugery, Sahmyook Medical Center, 82 Mangu-ro,

Dongdaemun-gu, Seoul 130-711, Korea

Tel: +82-2-2210-3563, Fax: +82-2-2212-2673

E-mail: hwangyon@hotmail.com

(C) 2015 The Korean Society of Coloproctology

This is an open-access article distributed under the terms of the Creative Commons Attribution NonCommercial License (http://creativecommons.org/licenses/by-nc/3.0) which permits unrestricted noncommercial use, distribution, and reproduction in any medium, provided the original work is properly cited. 